DIVISION OF THE HUMANITIES AND SOCIAL SCIENCES CALIFORNIA INSTITUTE OF TECHNOLOGY

PASADENA, CALIFORNIA 91125

Uncertainty and Political Perceptions

R. Michael Alvarez

California Institute of Technology

Charles $\mathrm{H}$. Franklin

University of Wisconsin-Madison

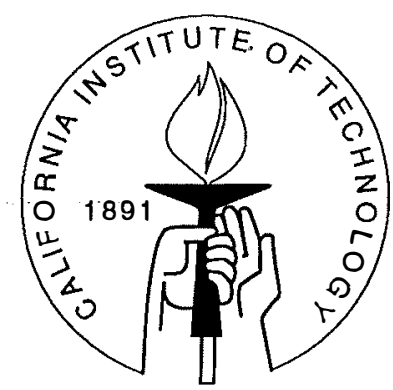

SOCIAL SCIENCE WORKING PAPER 844

April 1993 


\title{
Uncertainty and Political Perceptions
}

\author{
R. Michael Alvarez \\ Charles H. Franklin
}

\begin{abstract}
The world of politics is uncertain. Citizens are only imperfectly informed about current governmental actions and about the promises of politicians regarding future courses of public policy. Politicians and candidates, moreover, often have incentives to disseminate ambiguous and perhaps inconsistent information. Previous work, both theoretical and empirical, has largely failed to incorporate this uncertainty into the analysis of public opinion and electoral behavior. In this paper we discuss measures designed to elicit the uncertainty survey respondents feel about their political perceptions. These measures demonstrate response patterns which are interpretable and substantively interesting. Also, the response patterns are consistent with a model relating uncertainty to citizen information costs. And last, these measures allow us to understand the stated perceptions of respondents in novel and important ways.
\end{abstract}




\title{
Uncertainty and Political Perceptions *
}

\author{
R. Michael Alvarez \\ Charles H. Franklin
}

\section{Introduction}

Citizens face an inherently uncertain political world. In discussions of policy choices, the effects of various policies and even the choices themselves are never known with certainty. Politicians and candidates are often unclear about their positions, becoming "addicted to equivocation and ambiguity" (Key 1958), and the course of future events is always imperfectly anticipated. Uncertainty is an inextricable aspect of political life.

Though faced with uncertainty, citizens are nonetheless frequently called upon to make consequential political choices. How they incorporate uncertainty into their perceptions and into their decision making, is the focus of our research. Our argument revolves around the premise that while uncertainty is ubiquitous, it can be measured, and the variation that exists in uncertainty across individuals and political contexts rests in systematic differences in cognitive processes and the objective political world of the citizen. Our purpose here is to develop measures of uncertainty, to examine their properties and show that they are consequential for both survey responses and for models of candidate perception.

Uncertainty has been discussed in the social choice and game theoretic literatures in the form of imperfect and incomplete information. However, the behavioral and empirical literatures have largely ignored imperfect information except to stress the prevalence of nonattitudes or limited cognitive capacities. Ignoring the ubiquity of uncertainty in political preferences and decision making is misguided if our premise is correct that citizens are never certain about their political choices. It is theoretically misguided as well, if politics is inherently uncertain.

${ }^{*}$ Previous versions of this paper were presented at the American Political Science Association Annual Meetings, Chicago, Illinois, September 1992, and the Ninth Political Methodology Conference, Harvard University, July 16-19, 1992. We thank Steve Ansolabehere, Stanley Feldman and Simon Jackman for their comments. We are especially indebted to the Letters and Science Survey Center of the University of Wisconsin, Madison, for support of our data collection. 
Knowing how informed a respondent is about politics is clearly important. The recent work of Zaller $(1989 ; 1991)$ and the earlier work of Converse (1962) both observed vast differences in the attitudes of respondents across various levels of information. Additionally, the ability of political campaigns to inform voters depends upon the amount of prior information held by an individual (Zaller 1989). Thus, it is obviously important to know the relative information levels of survey respondents, since differences in information produce known differences in attitudes and susceptibility to learning.

Additionally, in the growing research about the "theory of the survey response", it is apparent that respondents bring different levels of information to bear in their answers to survey questions. The recent work of Zaller and Feldman (1992) argues that respondents answer questions based on a stochastic sampling of the available information about the subject under inquiry. Those with more information about a particular topic should bring this information to bear in forming their survey response, which should produce a different pattern of responses than would an individual with little information.

But also of importance is the precision of the individual's information. That is, knowing relative levels of the reliability or certainty of a respondent's information is of critical significance for understanding their perceptions and their preferences. This has been shown in the growing theoretical and empirical research on the role of uncertainty in decision making (Alvarez 1992; Bartels 1986; Brady and Ansolabehere 1989; Enelow and Hinich 1984; Franklin 1991; Page 1978; Palfrey and Poole 1987; Shepsle 1972). In this research, uncertainty has played a pivotal role in models of decision making.

Yet in this focus on uncertainty and decision making, no consensus has emerged on how to measure uncertainty. The usual approach has been to estimate uncertainty by relying upon surrogates available in existing surveys. Bartels (1986) relies on "don't know" responses as indicators of uncertainty; Franklin (1991) makes use of available demographic and political indicators assumed to affect uncertainty; Alvarez (1992) combines direct measures of uncertainty with demographic exogenous variables. In each case, the analysis rests on the assumption that the exogenous variables are related to uncertainty. But since these demographic variables are usually only weakly related to uncertainty, the models tend to be rather fragile, of ten leading to large standard errors and frequent fluctuations in estimated coefficients.

Our solution to this measurement problem is to avoid these proxy measures and to go straight to the respondent with direct questions. In this paper we report on our efforts to develop new measures designed to probe citizen uncertainty about their own preferences, and about their perceptions of the positions of politicians, on important public policies. This novel attempt to measure uncertainty alleviates the inferential problems of earlier analyses, and leads to new conclusions about respondent perceptions. We also are able to relate our uncertainty measure to the nature of the survey response. In the next section of the paper we discuss the survey questions we developed, the methodology of the national telephone survey we undertook, and the response patterns these survey measures elicited. The subsequent sections contain a set of analyses designed to validate these as measures of uncertainty, and 
then to use the measures to better understand the policy perceptions of citizens. We close with a discussion of the implications of our research.

\section{Survey Measures of Imperfect Attitudes}

The data we analyze come from a national telephone survey conducted in the fall of 1991 and winter of 1992 by the Letters and Science Survey Center of the University of Wisconsin, Madison. The details of the survey are in the Appendix. Since part of our purpose was the development of new survey measures, we tested two alternative sets of uncertainty questions using randomly selected half samples for the two forms (Forms A and B). Each respondent was questioned about one of the U.S. Senators from their state, the Senator being randomly assigned. Respondents in both sub-samples were presented a series of questions concerning their preferences and their perceptions of the Senator's positions on two policy issues (tax increases and abortion) and on the liberal-conservative ideological dimension using a sevenpoint scale format. (See the appendix for question wording.)

The ordering of questions for each respondent was identical. They were first asked about their own position on the particular seven-point scale, and how certain they felt about their opinion. Then, they were asked to place the Senator, their certainty of the Senator's position, how much they had heard of the Senator's position, and the clarity with which the Senator has presented a position on the issue. The tax increase questions were posed first, followed by the abortion and the liberal-conservative questions. Our focus here is the uncertainty questions, and we do not present analyses concerning what the respondent heard of the Senator's position and the clarity of that position.

The question wording variation of concern in this analysis compares dichotomous response options with three ordinal categories in order to examine respondents' abilities to make finer distinctions about their level of uncertainty. ${ }^{1}$ After each seven-point placement of their own position, Form A respondents were asked "Have you completely made up your mind about where you stand on this, or is there still some doubt in your mind?" Form B respondents were asked: "Are you very certain of where you stand on this, pretty certain, or not very certain?" Next, following the placement of the Senator, we probed for uncertainty about that position. In Form A, the question read "Do you feel you know for certain what (Senator's name)

\footnotetext{
${ }^{1}$ Another question wording variant which we do not analyze in this paper concerned the wording of the seven-point scales. Form A respondents were read an introduction to the seven-point scale question designed to reveal the uncertainty in their perceptions, called "range formats", which are nearly identical to those employed in the 1980 National Election Study's Pilot Study. This question format was used in Form A for both the respondent's own position on each issue, as well as their perception of the senator's position. These invite the respondent to place themselves or the Senator within some range, rather than at a single point, if they feel uncertain about the exact position. Form B respondents were read introductions to the seven-point scale questions very similar to that encountered in the usual NES survey, not utilizing the "range formats." Unfortunately, the results of the range format were disappointing. Only $6.0 \%$ of respondents gave a range response for their own position on the tax increase issue, $4.8 \%$ on the abortion scale, and $6.9 \%$ on the liberal-conservative dimension. This compares to a $1.3 \%$ rate of unsolicited range placement in Form B on both the tax and abortion scales, and $2.6 \%$ on the liberal-conservative scale.
} 
position is on this, or is there still some doubt in your mind?" Form B respondents were asked "How certain are you of (Senator's name) position on this? Very certain, pretty certain, or not very certain?" These options deliberately parallel the options for the respondent's own position. ${ }^{2}$ Thus, Form A uses dichotomous response options for the uncertainty items, while form B uses an ordered trichotomy format. Both forms were randomly assigned to Senator 1 or Senator 2 to maximize variation in characteristics of the Senators we used as perceptual objects.

Following each seven-point scale, we asked all respondents about the certainty of their own perceptions, in different ways in each of the survey forms. Form A respondents were asked whether they had "doubts" about their opinion on the issue (with dichotomous response options), and Form B respondents were asked about the "certainty" of their position on the issue (trichotomous responses). The survey marginals for these questions are given in Table 1.

Examination of the Form A (top panel, Table 1) results shows first that many more respondents were certain of their opinions on the abortion scale than on the other two scales - $87.4 \%$ stated they had no doubts about their position on the abortion issue, relative to $58.4 \%$ on tax increases and $65.6 \%$ on the liberal-conservative scale. Also worth noting is the very low item non-response rate in the Form A format, with only $2 \%$ of respondents, or less, failing to provide an answer to this question.

The Form B results in Table 1, in the lower panel, give the marginals from the trichotomous format for this question. Again, notice the high degree of respondent certainty in their own opinion on the abortion issue. Over three-quarters of the respondents in this sub-sample stated they were very certain of their position, compared to $50.4 \%$ on the liberal-conservative scale and $41.8 \%$ on the tax increase issue. Also, there was a low item non-response rate on this question format as well, less than a percent on the first two dimensions, and less than two percent on the liberal-conservative scale. Each of these rates of item non-response are lower than the rates on the corresponding question in Form A. However, the results in the lower panel do seem to elicit a greater degree of respondent uncertainty than the format in the top question. The percentages of respondents indicating relative certainty in their opinions drops by between 10 and $15 \%$ in the Form B item; furthermore, in the Form B question, relatively large percentages say they are "pretty" certain of their opinions, especially in relation to tax increases and the liberal-conservative scale.

Respondents were next asked to place their Senator on the seven-point issue scale. Following this, we asked respondents how certain they were about their placement of the Senator. ${ }^{3}$

\footnotetext{
${ }^{2}$ We do not report analysis of the remaining questions, but describe them here for completeness. After the Senator uncertainty question, both Form A and Form B respondents were asked identical questions about how much they had heard of the senator's position: "How much have you heard about (Senator's name) position on this? A lot, some, or very little?" The final question wording variation followed this. For Form A respondents, we asked "Has (Senator's name) been pretty clear about (his/her) position on this, or hasn't (he/she) been very clear about that?" In Form B, this was changed to read "How clear has (Senator's name) been about (his/her) position on this? Has (he/she) been very clear, pretty clear, or not very clear?"

${ }^{3}$ Those who failed to place the Senator were not asked the certainty item, which accounts for the atten-
} 
These results are given in Table 2.

In the top panel (Form A), we see a considerable amount of uncertainty among those respondents who placed the senator on the scale. Approximately $60 \%$ of the respondents said they doubted their perception of the senator's position on abortion and the liberalconservative dimension, and $75 \%$ doubted their perception of the senator's position on increasing taxes. In the bottom panel is additional evidence of substantial levels of uncertainty about the positions of senators on these three scales. Almost $50 \%$ said they were not certain at all about their perception of the senator's position regarding a tax increase, with $43.6 \%$ and $27.7 \%$ giving the same answer on the abortion and liberal-conservative scales, respectively. Also, while $50.2 \%$ stated they were pretty certain about their senator's liberalconservative position, only $35 \%$ were equally certain about their perception of the senator on the other scales.

The differences in response patterns between the two forms is apparent in this table. While nearly equal proportions of Form A respondents chose the "some doubts" response for both abortion and ideology, the trichotomous measure used in Form B shows striking differences between these two. Close to $44 \%$ say they are not very certain on the abortion item, while only $28 \%$ say the same for liberal-conservative. The dichotomous measure makes uncertainty on these two items appear very similar, while the trichotomous measure points to substantial differences. This is evidence that we benefit, from a measurement perspective, by using the three point instrument. It also suggests that respondents can make more refined distinctions than are captured by a simple dichotomous measure.

In comparison with self-placements, uncertainty about Senator placements is far greater. In Table 1, no more than $10 \%$ said they were "not very certain" about their own position. Yet Table 2 shows no less than $28 \%$ and as many as half saying they are not very certain of the Senator's position. This demonstrates the vastly greater uncertainty concerning Senator's positions and it also shows that the "not very certain" option is a very useful category when uncertainty levels are high. While few used this category when describing themselves, its use is common when Senators are the object of uncertainty.

Before moving further in our analysis, we note some general conclusions about these pilot survey questions. First, the response patterns from these alternative formats provide prima facie evidence that they are eliciting the desired responses. Second, the amount of item nonresponse on the alternative formats is very low, meaning that we are not asking respondents questions which are so complex or confusing that they cannot provide an answer. Third, our measurement efforts support the trichotomous measure over the dichotomous format. Respondents answer each.with equal alacrity but the three point measure captures differences which are masked by the two category option. The three category measure also provides a greater range, which is actually used, as we saw by comparing the low uncertainty for self with the high uncertainty for Senators. These results have clear implications for our measures in future surveys.

uation in sample sizes. 
Aside from these measurement issues, we are also obtaining substantively important results from these survey questions. One major conclusion jumps out of these tables: while respondents seem surprisingly certain of their own positions on each of the issue scales, they appear to be quite unsure of their Senator's stand on these issues. This suggests that the locus of political uncertainty is less in what people think they want but more a matter of being unable to say with much confidence what is being offered by their elected representatives. This immediately raises the intriguing question of whether this uncertainty is due to simple lack of information or rather to deliberate ambiguity on the part of politicians. If the behavior of Senators is able to affect the perceived uncertainty, then we have strong evidence that uncertain candidate perceptions are not entirely the fault of the voter.

A second substantive conclusion from these simple data is that voters are not uniformly handicapped by non-attitudes or cognitive limitations. If respondents were in fact finding it difficult to understand our issues, we would expect them to exhibit similar levels of uncertainty about both themselves and the Senator. Instead, we find a dramatic contrast in uncertainty. This strongly suggests that when voters have sufficient information they are generally able to form rather confident positions. But when faced with either lack of information or ambiguous signals, their reported uncertainty soars. This rules out a simple non-attitudes explanation for our results and shows that uncertainty responses are able to discriminate across objects even within a single issue. ${ }^{4}$

\section{The Validity of the Uncertainty Survey Items}

In this section, we demonstrate that respondents vary in their measured uncertainty by information levels and information costs, and by the availability of contextual political information. Our approach validates the survey measures by showing that they tap into the factors they are designed to measure. Here, we show that the uncertainty items are correlated in expected ways with a set of explanatory variables (Cook and Campbell, 1979). These models demonstrate that there are systematic individual-level patterns in the responses to these questions. By finding that theoretically-generated hypotheses concerning respondent uncertainty are supported with these survey data, we are more confident that these question formats are measuring perceptual uncertainty.

To test these models, we use a set of explanatory variables accounting for demographic factors, political information held by the respondent, as well as the ideological extremity of the Senator, whether the Senator was a member of two relevant committees (Finance and Labor and Human Resources), and the length of time since the senator has had to face an election. ${ }^{5}$ Our hypotheses for these indicators follow the logic in Downs (1957): those individuals with lower information costs are expected to be better informed about

\footnotetext{
${ }^{4}$ It would be useful to relate our measures of uncertainty to response stability. Unfortunately we do not yet have the panel data required for such an analysis.

${ }^{\mathbf{5}}$ These were coded as follows: education 1 (less than high school degree), 2 (only high school degree), 3 (more than high school), 4 (post-high school degree); race 0 if white and 1 if minority; religion 1 if a Catholic or Baptist, 0 otherwise; political information 0 if unable to rate Rehnquist and 1 if able to rate Rehnquist,
} 
their political perceptions. Thus, those with higher educational levels, and more political information, are expected to be more certain in their perceptions. The minority status and gender variables are surrogates for a variety of socio-economic conditions which tend to increase the costs of information. The religion indicator is intended to show that those who are members of certain religious groups might be better informed about the abortion issue than others.

The data about the Senators is from Congressional Quarterly Weekly Report, May 1992. The ADA scale was folded into an ideological extremity index. The variable for the senator's last electoral stand is the difference between the year of their last election and the current year. The committee membership variables are dummy indicators for two policyrelevant committees, Senate Finance (taxes) and Labor and Human Resources (abortion). Our hypotheses regarding these indicators were respondents with more ideologically extreme representatives, those with the most recently elected senators, and those with Senators who are policy specialists on tax and social policies, should be more confident in their perceptions of their representatives than other respondents, either through a cognitive inference process drawing upon this information about their representative, or through greater information about the Senator's position on these issues. In our subsequent analysis we employ a one-tail test, since we specify the direction of the effects we expect. Since our sample for each questionnaire form is quit limited, at around 200 cases, we also allow a generous .10 significance level. ${ }^{6}$

Modeling the response patterns to the uncertainty items was quite complicated, and a number of methodological decisions were needed to insure that we correctly modeled the particular items. The first set of models concern the respondent's uncertainty about their own positions. Form A respondents were only given a binary choice to the "doubts" about their position on the seven-point scale question, which we coded so that the high category contained those who were completely certain of their perceptions, and the low category those who "still had some doubt." Binary probit models were estimated to examine the impact of our independent variables on these responses. However, the Form B responses use three ordered response categories for this uncertainty question. We coded the responses so that the high category was the most "certain" response, and the low the least "certain." Given the ordered nature of this categorical variable, we estimated ordered probit models for these survey items following McKelvey and Zavoina (1975). The Form A respondent perceptual uncertainty models are in Table 3, and for Form B in Table 4. These tables are organized into three columns, where the first column gives the maximum-likelihood estimates and their associated standard errors for the tax increase question, the middle column for the abortion item, and the last column for the liberal-conservative item.

Table 3 presents mixed results. The general pattern in these models is for either or

following the approach advocated by Zaller (1990, 1991); Senator's ideological extremity was given by a folded ADA scale, where 0 indicated extreme and 50 moderate; Finance Member 0 if non-member Senate Finance and 1 if member; Labor and H. R. Member 0 if non-member Labor and Human Resource and 1 if member; and last election was calculated as the year of the senator's last election minus 1992.

${ }^{6}$ All of the models in this paper were estimated in Dubin and Rivers' SST, version 2.0. 
both education and political information to be correctly signed and statistically significant, meaning that those with lower information costs are more likely to be more certain about their own positions on these three issues. However, in Table 4 we find more supportive evidence that these survey responses are systematically related to our independent variables. Here, almost all of the variables are correctly signed and are usually statistically significant. The implications from this table are also that those with lower information costs are more certain in their own positions. The stronger results in Table 4 also support our earlier conclusion that the three point measure is more reliable than the dichotomous measure.

There is one substantively interesting pattern in these tables. We have hypothesized that generally our two minority status variables - for gender and race - should reflect socio-economic factors leading individuals in these groups to have higher information costs. But this hypothesis is not always true across issue dimensions; that is, there appears to be heterogeneity in the amount of uncertainty these two groups have about their own positions. For racial minorities, in both survey forms, it is apparent that they are more certain of their tax positions than whites, while less certain of their ideological and abortion positions, ceteris paribus. Further, women are more certain of their positions than men on abortion, but less certain than men on the tax position while the ideological position results show no consistent difference. It is not much of a stretch to conclude that these breaks in the pattern are due to the peculiar relationships of these groups to the particular issues. While our evidence is surely tentative, it is perhaps not too great a leap to conclude that where issues touch more directly on the individual, preferences are likely to be more precisely defined.

These results, while far from overwhelming, lend some support to our claims of valid measurement. The criterion variables we have used to predict uncertainty generally have the expected sign and are often significant. This is particularly true for the three point measure of Form B, while the Form A measure is less adequate. This is in keeping with our earlier conclusion that the dichotomous measure was missing important variation which was picked up by the three point variable.

Next, we estimated similar models examining the uncertainty responses for the Senator's issue positions. One problem for estimation of the response models is the presence of selection bias. The selection process in these items occurred because respondents who did not place the senators were not asked the subsequent uncertainty items. Since we would expect that many of those not placing the Senator did so due to a lack of information, the result would be an attenuation of the model estimates - we would systematically underestimate the influence of the variables on the particular survey response (Dubin and Rivers 1990). Therefore we needed to take the selection bias in these items into account in our estimation. Here, we present tobit models of the trichotomous uncertainty items (Dubin and Rivers 1990; Tobin 1958). These models assume that the variable being censored is continuous, but our trichotomous response items are only an approximation of a continuous phenomenon. We nonetheless treat the uncertainty measure as continuous because we think it more important to deal with the selection bias problem than to insist on the merely ordinal measurement. The technology for combining the tobit model with an ordered probit outcome remains somewhat beyond our reach (but see Dubin and Rivers 1990 for a preliminary road map.) 
We estimated tobit models for the Form B uncertainty items, and these are presented in Table 5.

Among the demographic variables, the indicator for gender is negatively signed and statistically significant in all models, while the religion indicator is positive and significant in the abortion equation, both as expected. Similarly, the political information indicator is positive and strongly significant in all models. The committee membership indicator is correctly signed, but statistically significant only for abortion. There is, however, no indication that recency of election plays any role. Contrary to our expectations, the ideological extremity indicator is always positive, and twice significant, indicating that respondents were more certain of more moderate senators. ${ }^{7}$

Comparison of the models of the respondent's certainty of their self-placement with the placement of the senator, brings out interesting conclusions. One conclusion returns to the discussion above about our expectations for both the minority and gender parameter estimates. In the models of respondent self-placement uncertainty, we found that women tended to be more uncertain on tax increases and ideology, but less uncertain on the abortion item. However, across the board, women tended to be more uncertain of their placement of the senators than were men. The race coefficients show a similar, if less dramatic, pattern of no difference, though there were differences when asked about the self. This evidence shows that if an issue is salient for a social group, those in the particular "issue public" may be more certain of their own positions but they are not necessarily more certain of the positions of their elected representatives.

We demonstrated in this section that the measures we advocate for directly measuring perceptual uncertainty are related to various criterion variables in reasonably predictable ways. This was accomplished through a series of models in which we have shown that the responses in our survey to these questions varied systematically across respondents, in the patterns we would expect were these questions measuring uncertainty. Therefore, we can feel reasonably confident that our questions are valid measures of perceptual uncertainty. However, there remains the issue of the utility of these measures for our understanding of substantive responses to politicians. This is the topic of the next section.

\footnotetext{
${ }^{7}$ This particular results is a puzzle not only since it is counter to our expectations, but also since it was not apparent in our preliminary analyses which did not account for the selection process. Thus, this suggests that the selection process might account for the direction of this estimate. For example, to place a moderate on an issue scale, the respondent needs a good deal of information - but not so for an extremist. Since placement on a scale is correlated with information, it necessarily has a greater effect among those who need more information to place the senator, the moderates. We observe greater certainty for moderate senators, then, because we only observe the placement if the voter has a good deal of information and is relatively certain of their placement.
} 


\section{Uncertainty and the Perception of Political Figures}

While uncertainty may be ubiquitous it would remain uninteresting if it were without consequences. In this section we demonstrate two consequences of uncertainty for the perception of political figures. First we consider the effect of uncertainty on the distribution of responses. Second, we show that perceptions are structured differently among the certain and uncertain respondents.

There has been little work to guide our efforts in this area. The primary avenue through which respondent uncertainty might influence perceptions has been described by a handful of researchers (Alvarez 1992; Bartels 1988; Franklin 1991; Shepsle 1972). This work has conceptualized respondent perceptions as probability distributions, with a central tendency and a variance. The larger the variance the greater the uncertainty.

There are two ways in which respondents might answer survey questions based on this model. First, respondents might draw an observation from the distribution and report the position drawn. We call this the "random sampling" response model. Such a model would be generally compatible with the survey response model developed by Feldman and Zaller (1992). The variability in individual responses would thus provide an indicator of the underlying respondent uncertainty, which we could estimate. ${ }^{8}$ This model was used by Franklin (1991) to estimate campaign-induced uncertainty.

Alternatively, respondents might report the central tendency of their distribution of perceptions, which we call the "expected value" response model. In this case, the variance of the distribution would be independent of the expected value. Thus the observed responses would tell us little about the underlying uncertainty. For example, two respondents might both have a perceptual distribution centered at the same point, while one has a large variance and the other a small variance. If respondents report the expected value, then both will provide the same reported perceptions.

While the variance and expected value are independent in principle, in practical survey situations they are related. A natural way to represent maximum uncertainty on a sevenpoint issue scale is as a uniform distribution. Such a distribution naturally leads to an expected value of 4.0. Thus if respondents report expected values, we should expect the most uncertain to report positions concentrated around 4 on our issue scales. If respondents sample randomly from the entire distribution however, as predicted by the first response model, we should see responses spread more or less evenly across the issue scale. In either case, uncertainty would have significant consequences for our survey measures.

Our first cut at this effect is presented in Tables 6 and 7. Here we simply present the distribution of perceived Senator positions by our measures of uncertainty. The chi-square test confirms what is apparent to the eye: respondents who say they are more uncertain of the Senator's position have a increased affinity for placing the Senator near the midpoint on

\footnotetext{
${ }^{8}$ Alternatively, several samples could be taken and the mean of these samples could be reported. In either case, the variance of the responses would be related to the variance of the underlying distribution.
} 
each issue scale. This effect is especially pronounced for the form B uncertainty measure in Table 7.

As a rough cut, these results offer greater support for the expected value response model than for the random sampling model. However, they suffer from the fact that there is variability in the objects of perception which are not accounted for in the table. This is most apparent from the "certain" column of table 7 which appears to suggest that high certainty respondents are apt to pick one extreme or the other. This is misleading, however, for it is likely that respondents who place their Senator at 1 are responding to a different Senator from those who place their Senator at 7.

To remove this confounding effect, while estimating the impact of uncertainty on responses, we used an unordered logit model. In these models, we estimate the relative probabilities that a respondent would place their senator at one point on the seven-point scale relative to a baseline position. Here we chose the extreme liberal position as our baseline category, so the probabilities are all relative to this liberal position. Also, to ensure that the patterns observed in Tables 6 and 7 are not artifacts of either informational differences across respondents or objective differences in the ideology or party of the senators, we included control variables for information, senator ideology, and senator party (all measured as before). These results are presented in Table 8 for the Liberal-Conservative issue scale. ${ }^{9}$ The consistent pattern of negative uncertainty coefficients for categories 3,4 and 5 confirm the results from the simple cross tabulations: the more uncertain the respondent, the more apt they are to gravitate towards the middle of the scale. This is consistent with the expected value survey response model but not with the random sampling model.

We believe that this finding regarding the uncertain respondents is quite profound. It has implications for how we understand the survey response and for how we model respondent perceptions of political figures on policy issues. For it is clear that uncertain individuals are more likely to state that their senator has a moderate position on the scale, regardless of the "actual" position of the senator (as given by the interest group ratings here) and the party of the senator. This heterogeneity in responses must be incorporated into models of perceptions.

To demonstrate the strength of this claim, we estimated a standard model of ideological perceptions, similar to that advanced by Franklin (1991). Here, the respondent's perception of the Senator's ideological position is assumed to be a linear function of the senator's "actual" position as given by the interest group ratings, the senator's party, the respondent's own ideological position, and the interaction between the respondent's position and their evaluation of the senator. The first two variables in the perceptual model account for the influence of "objective" information on the respondent's perceptions, while the last two account for projection effects.

This model of perceptions was estimated separately for respondents who were uncertain

\footnotetext{
${ }^{9}$ The results are similar for the abortion and tax scales. These are available on request.
} 
about their perceptions and those who were certain about their perceptions. ${ }^{10}$ The null hypothesis is that these two models should show identical effects of the independent variables on respondent perceptions. The alternative hypothesis, however, is that since uncertain respondents tend to provide a midpoint placement of the senator, the model should have a very poor fit for them, while it should have a relatively good fit for the certain respondents.

The estimates of these models are in Table 9. The Form A models are in the second and third column, and the Form B in the fourth and fifth columns. For uncertain respondents in both survey forms the perceptual models fit the data very poorly. In fact, only one variable, that for the senator's party, is statistically significant (and it is significant in only the Form $\mathrm{B}$ model). The adjusted $R^{2}$ statistics for both models $(0.04$ and 0.00$)$ demonstrate the lack of fit.

This stands is sharp contrast to the models for the certain respondents. These two models fit the data relatively well. The adjusted $R^{2}$ statistics are much larger $(0.42$ and 0.23 , respectively by Form), indicating that the independent variables do a reasonable job of predicting where respondents place their senators on the ideological scale. Furthermore, it is interesting to note that the more certain respondents rely on both objective information, as measured by the Senator's ideology, as well as projection processes, in developing their perception of the Senator. But the important conclusion is that we can clearly reject the null hypothesis and conclude that the parameters of the perceptual model depend upon respondent uncertainty.

\section{Conclusion: Uncertainty and Political Perceptions}

In this paper we have shown that it is possible to measure subjective uncertainty using practical survey items. The ubiquity of uncertainty in politics, increasingly recognized in theoretical models of elections and decisions, makes such measures highly desirable.

The survey-based measures we have discussed in this paper have several virtues. The first is that they clearly are valid measures of uncertainty, since they are yield explicable response patterns and are systematically related to individual information costs and objective aspects of the perceptual objects. Our experimentation with different formats, moreover, indicated that the trichotomous measures are preferred.

A second virtue of these measures is that they would cost little to include in future survey instruments. Unlike some survey approaches to measuring uncertainty, like the "range formats" (Alvarez 1992; Aldrich et al. 1982), the use of these measures of uncertainty would not involve altering the structure of the seven-point policy scales nor would they destroy the historical continuity of issue and ideology measurement in surveys such as the National Election Studies. In fact, all that is required to obtain measures of uncertainty

\footnotetext{
${ }^{10}$ Due to the relative paucity of respondents in Form B who claimed certainty about their perception, we considered both the "pretty" certain and the "certain" responses to be indications of relative certainty.
} 


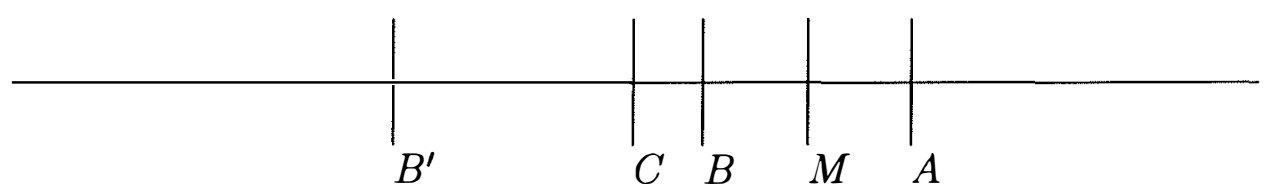

Figure 1: Alternative Candidate Types

is an additional handful of questions. Further, they can be used with any issue question format, whether seven-point, branching or anything else.

A third virtue of these measures is that they reveal patterns in survey responses which have previously gone unnoticed. More importantly, they offer substantive and theoretically based explanations for these patterns. While we set out to examine respondent uncertainty, we found that uncertainty could also speak to theories of the survey response.

Finally, our results may cast light on previously perplexing findings. Shepsle 1972 and others have sought to explain when candidates might have incentives to equivocate and project ambiguity in their issue positions. For the most part, these results depend on at least some voters being risk acceptant. These results have proven puzzling in light of other theoretical reasoning which predict that uncertainty is generally harmful to a candidate's chances (Enelow and Hinich 1981; Bartels 1986). At the same time, it is widely believed that candidates in fact do equivocate and often seek to muddy their positions. How can these seemingly contradictory results be resolved?

Our results suggest a possible solution to this problem. If voters respond to uncertainty as our findings suggest, then the effect of uncertainty is to lead some voters to view candidates as centrists. Under the usual spatial model conception, voter utility for candidates is a function of the distance between the candidate and the voter's ideal point minus a penalty for uncertainty (Enelow and Hinich, 1981; Bartels, 1986). Our results suggest that candidates might strategically trade perceived distance for uncertainty. By being more ambiguous an extreme candidate suffers a penalty for uncertainty but gains points by appearing to uncertain voters as more centrist. This type of candidate is illustrated by point $A$ in Figure 1. In the figure; point $C$ is the centrist position on the issue and point $M$ is the median voter. Those with an incentive to equivocate must balance the advantages of appearing more moderate against the costs born of the greater uncertainty. Thus extreme uncertainty is never an advantage for it must eventually outweigh the positional gains. But some equivocation will prove an advantage for some candidates.

This also suggests asymmetric strategies across candidate types. Candidates who are 
more extreme than the median voter ( $A$ in Figure 1 ) may seek to muddy the waters in order to be perceived as more moderate, and hence closer to the median voter. In contrast, candidates who are more moderate than the median voter (such as point $B$ in Figure 1) might attempt to be as clear as possible about their positions, for any additional uncertainty will draw their perceived position further from the median voter while also suffering the penalty for uncertainty.

Finally, candidates who are far apart, with both the median voter and the centrist position between them ( $B^{\prime}$ and $A$ in Figure 1), might both have incentives to equivocate. Note, however, that there are additional limits to equivocation here. At most, equivocation can make candidate $B^{\prime}$ appear to be at point $C$. Further equivocation can only incur penalties for uncertainty, not move the perceived location closer to $M$. Candidate $A$ can, however, match the position of the median voter by using just the right amount of equivocation. Exactly how much uncertainty each candidate induces depends on the relative sensitivity of the voters' utilities to location and uncertainty. The higher the penalty for uncertainty the less equivocation, as we would expect. Interestingly, however, the more emphasis voters place on candidate position, ceteris paribus the more candidate $B^{\prime}$ equivocates, while candidate $A$ equivocates only until her perceived position matches $M$.

Thus our empirical finding, that uncertainty leads to more centrist perceptions rather than simply greater variance about an unchanged expected value, has led us to a tentative solution to a theoretical conundrum. Future development of these measures may provide further insights into the effects of uncertainty in politics. 


\section{Appendix}

The survey was conducted by professional interviewers at the University of Wisconsin Letters and Sciences Survey Center. A national probability sample of 797 adults from the 48 contiguous states were interviewed by telephone. A CATI system provided randomization of survey forms as described in the paper. $53.2 \%$ of the sample was assigned to the first survey group and $46.8 \%$ were assigned to the second group. The $6.4 \%$ difference in assignment rates seems to have been due to the tendency of the random number generator used by the survey organization to be marginally more likely to choose positive numbers, all of which were assigned to the first survey group. The assignment of respondents to a randomly-selected senator was less troublesome: in Form A respondents, 50.5\% were assigned to Senator 1 and $49.5 \%$ to Senator 2; for Form B respondents, $52.4 \%$ were assigned to Senator 1 and $47.6 \%$ to Senator 2. Under the assumption that the sampling mechanism employed provides roughly the same accuracy as simple random sampling, this produces a confidence interval of $\pm 3.5 \%$ on a typical sample proportion. The survey was in the field from October 2,1991 until March 5, 1992, with the bulk of interviewing occurring in November and February. The sample obtained corresponds quite closely to the population of American adults on a number of demographic dimensions. However, our sample appears to contain decidedly better educated respondents, and somewhat fewer minorities, than a representative sample should.

Table 10 presents the demographic profile of the survey we conducted. The first column gives the number of respondents, and the second gives the corresponding percentages. The third column presents identical percentages, taken from the Statistical Abstract of the United States, 1991. As we discussed briefly in the text, this sample is quite representative of the American adult population on most dimensions. Our sample contains better educated respondents, and fewer minorities, than desired. This could be the result of any number of processes, including the sampling procedure, the fact that we conducted a telephone interview, and the problem of survey non-response. It is important to note, though, that even larger-scale academic survey organizations have the same difficulties obtaining representative samples. In 1988, the National Election Studies Presidential Pre-Election sample contained $57.3 \%$ females, and only $42.7 \%$ men, which is more skewed toward female representation than our sample; the marginals from the education items in the 1988 NES were also quite skewed, with $22.0 \%$ having less than a high school degree, $35.7 \%$ a high school degree, $16.8 \%$ some post-high school education, and $25.5 \%$ a post-high school degree. However, the 1988 NES was able to almost perfectly replicate the racial profile of the adult population, with $83.2 \%$ white representation, $13.2 \%$ black, and $3.6 \%$ from other races.

The wording-of-our seven point scales is presented below:- These were modified for Form A to encourage "range" responses. Since this does not figure in the current paper we present only the Form B wording. To measure the Senator's perceived position the question was modified by prefixing "What about Senator Senator's name from your state? Where would you place Senator's name on this scale...".

Taxes: Some people feel that the federal government should not raise taxes under any 
circumstances. Others feel that a tax increase is required to reduce the deficit and pay for needed programs. Where would you place yourself on a scale from one to seven, where 1 means you feel taxes should not be raised under any circumstances and 7 means you feel that a tax increase is required to reduce the deficit and pay for needed programs?

Abortion: Some people feel that abortions should be illegal. Others feel that there should be no restrictions on a woman's right to an abortion if she wants one. Where would you place yourself on a scale from one to seven, where 1 means you feel abortions should be illegal and 7 means you feel that there should be no restrictions on a woman's right to an abortion?

Liberal/Conservative: In politics, some people have very liberal political views while other people have very conservative political views. Where would you place yourself on a scale from one to seven, where 1 means you have very liberal political views and 7 means you have very conservative political views?

This survey was in the field from October 2, 1991 until March 5, 1992. A monthly profile of the sampling period shows the following distribution: in October 1991, 25 respondents were interviewed, $3.1 \%$ of the sample; in November 1991, 279 interviews, $35.0 \%$; in December 1991, 104 interviews, 13.0\%; in January 1992, 144 interviews, 18.1\%; in February 1992, 214 interviews, 26.9\%; and in March 1992, 31 interviews, $3.9 \%$. 
Table 1: Survey Representativeness Sample Aggregates Versus Census Profile

\begin{tabular}{|c|c|c|c|}
\hline "Dimension & Sample No. & Sample \% & Census \% \\
\hline \multicolumn{4}{|l|}{ Gender } \\
\hline Male & 365 & $45.8 \%$ & $48.7 \%$ \\
\hline Female & 432 & $54.2 \%$ & $51.3 \%$ \\
\hline \multicolumn{4}{|l|}{ Race } \\
\hline White & 700 & $87.8 \%$ & $84.2 \%$ \\
\hline Black & 61 & $7.7 \%$ & $12.4 \%$ \\
\hline Other Races & 29 & $3.6 \%$ & $3.5 \%$ \\
\hline \multicolumn{4}{|l|}{ Age } \\
\hline $18-29$ & 165 & $21.0 \%$ & $23.0 \%$ \\
\hline 30-39 & 201 & $25.6 \%$ & $23.7 \%$ \\
\hline $40-49$ & 157 & $20.0 \%$ & $17.2 \%$ \\
\hline $50-59$ & 90 & $11.5 \%$ & $12.5 \%$ \\
\hline $60-69$ & 96 & $12.2 \%$ & $11.9 \%$ \\
\hline 70 and above & 6 & $9.7 \%$ & $11.8 \%$ \\
\hline \multicolumn{4}{|l|}{ Education } \\
\hline Less Than HS & 84 & $10.6 \%$ & $47.7 \%$ \\
\hline HS Degree & 162 & $20.4 \%$ & $31.1 \%$ \\
\hline Some Post-HS & 202 & $25.4 \%$ & $10.6 \%$ \\
\hline Post-HS Degree & 348 & $43.7 \%$ & $10.7 \%$ \\
\hline \multicolumn{4}{|l|}{ Region } \\
\hline North East & 164 & $20.6 \%$ & $20.4 \%$ \\
\hline Midwest & 207 & $26.0 \%$ & $24.0 \%$ \\
\hline South & 246 & $30.9 \%$ & $34.4 \%$ \\
\hline West & 172 & $21.6 \%$ & $21.2 \%$ \\
\hline
\end{tabular}


Table 2: Respondent Uncertainty Of Own Position Response to Form A "Certainty" Question

\begin{tabular}{|c|c|c|c|c|c|c|}
\hline & Taxes & $\overline{\text { Taxes }}$ & Abortion & Abortion & Lib/Con & Lib/Con \\
\hline Response & $\mathrm{N}$ & $\%$ & $\mathrm{~N}$ & $\%$ & $\mathrm{~N}$ & $\%$ \\
\hline Certain & 229 & $58.4 \%$ & 354 & $87.4 \%$ & 265 & $65.6 \%$ \\
\hline Doubts & 155 & $39.5 \%$ & 44 & $10.9 \%$ & 128 & $31.7 \%$ \\
\hline DK & 7 & $1.8 \%$ & 3 & $0.7 \%$ & 6 & $1.5 \%$ \\
\hline $\mathrm{NA}$ & 1 & $0.3 \%$ & 4 & $1.0 \%$ & 5 & $1.2 \%$ \\
\hline Totals & 392 & & 405 & & 404 & \\
\hline \multicolumn{7}{|c|}{ Response to Form B "Certainty" Question } \\
\hline & Taxes & Taxes & Abortion & Abortion & Lib/Con & Lib/Con \\
\hline Response & $\mathrm{N}$ & $\%$ & $\mathrm{~N}$ & $\%$ & $\mathrm{~N}$ & $\%$ \\
\hline Very & 146 & $41.8 \%$ & 272 & $77.7 \%$ & 180 & $50.4 \%$ \\
\hline Pretty & 166 & $47.6 \%$ & 68 & $19.4 \%$ & 144 & $40.3 \%$ \\
\hline Not & 35 & $10.0 \%$ & 8 & $2.3 \%$ & 27 & $7.6 \%$ \\
\hline DK & 1 & $0.3 \%$ & 1 & $0.3 \%$ & 1 & $0.3 \%$ \\
\hline NA & 1 & $0.3 \%$ & 1 & $0.3 \%$ & 5 & $1.4 \%$ \\
\hline Totals & 349 & & 350 & & 357 & \\
\hline
\end{tabular}

Table 3: Respondent Uncertainty Of Senator's Position Response to Form A "Certainty" Question

\begin{tabular}{|c|c|c|c|c|c|c|}
\hline & Taxes & Taxes & Abortion & Abortion & $\mathrm{Lib} / \mathrm{Con}$ & Lib/Con \\
\hline Response & $\mathrm{N}$ & $\%$ & $\mathrm{~N}$ & $\%$ & $\mathrm{~N}$ & $\%$ \\
\hline Certain & 54 & $23.3 \%$ & 59 & $36.4 \%$ & 98 & $37.8 \%$ \\
\hline Doubt & 174 & $75.0 \%$ & 99 & $61.1 \%$ & 156 & $60.2 \%$ \\
\hline DK & 4 & $1.7 \%$ & 4 & $2.5 \%$ & 5 & $1.9 \%$ \\
\hline NA & 0 & $0.0 \%$ & 0 & $0.0 \%$ & 0 & $0.0 \%$ \\
\hline Totals & 232 & & 162 & & 259 & \\
\hline \multicolumn{7}{|c|}{ Response to Form B "Certainty" Question } \\
\hline & Taxes & Taxes & Abortion & Abortion & Lib/Con & Lib/Con \\
\hline Response & $\mathrm{N}$ & $\%$ & $\mathrm{~N}$ & $\%$ & $\mathrm{~N}$ & $\%$ \\
\hline Very & 24 & $12.2 \%$ & 35 & $21.5 \%$ & 46 & $21.2 \%$ \\
\hline Pretty & 72 & $36.6 \%$ & 55 & $33.7 \%$ & 109 & $50.2 \%$ \\
\hline Not & 98 . & $49.8 \%$ & 71 & $-43.6 \%$ & 60 & $27.7 \%$ \\
\hline DK & 1 & $0.5 \%$ & 2 & $1.2 \%$ & 1 & $0.5 \%$ \\
\hline $\mathrm{NA}$ & 2 & $1.0 \%$ & 0 & $0.0 \%$ & 1 & $0.5 \%$ \\
\hline Totals & 197 & & 163 & & 217 & \\
\hline
\end{tabular}


Table 4: Probit Models of Form A Respondent Certainty

\begin{tabular}{|c|c|c|c|}
\hline $\begin{array}{r}\text { Ind. } \\
\text { Variables }\end{array}$ & Taxes & Abortion & Lib-Con \\
\hline Intercept & $\begin{array}{c}0.11 \\
(0.23)\end{array}$ & $\begin{array}{c}0.47^{* *} \\
(0.27)\end{array}$ & $\begin{array}{l}-0.03 \\
(0.23)\end{array}$ \\
\hline Gender & $\begin{array}{l}-0.13 \\
(0.13)\end{array}$ & $\begin{array}{c}0.13 \\
(0.17)\end{array}$ & $\begin{array}{c}0.04 \\
(0.13)\end{array}$ \\
\hline Education & $\begin{array}{c}0.03 \\
(0.07)\end{array}$ & $\begin{array}{l}0.24^{* *} \\
(0.08)\end{array}$ & $\begin{array}{c}0.13^{* *} \\
(0.07)\end{array}$ \\
\hline Race & $\begin{array}{c}0.20 \\
(0.21)\end{array}$ & $\begin{array}{l}-0.06 \\
(0.26)\end{array}$ & $\begin{array}{l}-0.16 \\
(0.21)\end{array}$ \\
\hline $\begin{array}{r}\text { Political } \\
\text { Info }\end{array}$ & $\begin{array}{c}0.20^{*} \\
(0.13)\end{array}$ & $\begin{array}{r}0.005 \\
(0.18)\end{array}$ & $\begin{array}{c}0.18^{*} \\
(0.14)\end{array}$ \\
\hline $\operatorname{LLR}($ d.f. $)$ & $13.5(4)^{* *}$ & $14.4(4)^{* *}$ & $15.9(4)^{* *}$ \\
\hline$\%$ corr. & 60.2 & 89.1 & 67.8 \\
\hline
\end{tabular}

Note: * denotes estimates significant at $\mathrm{p}=0.10,{ }^{* *}$ denotes significant at $\mathrm{p}=0.05$, both one-tailed tests. Standard errors in parentheses. 
Table 5: Probit Models of Form B Respondent Certainty

\begin{tabular}{r|c|c|c} 
& \multicolumn{2}{|c}{} \\
\hline Variables & Taxes & Abortion & Lib-Con \\
\hline Intercept & $0.87^{* *}$ & $1.5^{* *}$ & $0.86^{* *}$ \\
& $(0.22)$ & $(0.27)$ & $(0.22)$ \\
Gender & $-0.22^{* *}$ & $0.31^{* *}$ & -0.15 \\
& $(0.13)$ & $(0.16)$ & $(0.13)$ \\
Education & $0.15^{* *}$ & 0.08 & $0.24^{* *}$ \\
& $(0.06)$ & $(0.07)$ & $(0.06)$ \\
Race & $0.41^{* *}$ & $-0.31^{*}$ & $-0.26^{*}$ \\
& $(0.20)$ & $(0.22)$ & $(0.20)$ \\
Political & 0.10 & $0.32^{* *}$ & 0.16 \\
Info & $(0.13)$ & $(0.16)$ & $(0.14)$ \\
$\mu$ & $1.5^{* *}$ & $1.3^{* *}$ & $1.5^{* *}$ \\
& $(0.10)$ & $(0.15)$ & $(0.11)$ \\
\hline LLR.(d.f.) & $19.7(4)^{* *}$ & $17.1(4)^{* *}$ & $38.7(4)^{* *}$ \\
$\%$ corr. & 53.3 & 78.1 & 52.6
\end{tabular}

Note: ${ }^{*}$ denotes estimates significant at $\mathrm{p}=0.10,{ }^{* *}$ denotes significant at $\mathrm{p}=0.05$, both one-tailed tests. Standard errors in parentheses. 
Table 6: Tobit Models of Form B Responses: Certainty of Senator's Position

\begin{tabular}{|c|c|c|c|}
\hline $\begin{array}{r}\text { Independent } \\
\text { Variables }\end{array}$ & Taxes & Abortion & Lib-Con \\
\hline Intercept & $\begin{array}{c}0.41 \\
(0.35)\end{array}$ & $\begin{array}{l}-0.49 \\
(0.48)\end{array}$ & $\begin{array}{c}0.66^{* *} \\
(0.36)\end{array}$ \\
\hline Education & $\begin{array}{l}-0.04 \\
(0.08)\end{array}$ & $\begin{array}{c}0.06 \\
(0.11)\end{array}$ & $\begin{array}{c}0.05 \\
(0.09)\end{array}$ \\
\hline Race & $\begin{array}{c}0.22 \\
(0.27)\end{array}$ & $\begin{array}{c}0.10 \\
(0.34)\end{array}$ & $\begin{array}{l}-0.13 \\
(0.28)\end{array}$ \\
\hline Gender & $\begin{array}{l}-0.67^{* *} \\
(0.18)\end{array}$ & $\begin{array}{l}-0.58^{* *} \\
(0.23)\end{array}$ & $\begin{array}{l}-0.77^{* *} \\
(0.18)\end{array}$ \\
\hline Political & $0.66^{* *}$ & $1.0^{* *}$ & $0.71^{* *}$ \\
\hline Information & $(0.18)$ & $(0.23)$ & $(0.19)$ \\
\hline Ideological & $0.01 * *$ & $0.01 *$ & 0.003 \\
\hline Extremity & $(0.006)$ & $(0.007)$ & $(0.006)$ \\
\hline $\begin{array}{r}\text { Finance } \\
\text { Committee }\end{array}$ & $\begin{array}{c}0.06 \\
(0.21)\end{array}$ & & \\
\hline $\begin{array}{l}\text { Labor - H.R. } \\
\text { Committee }\end{array}$ & & $\begin{array}{c}0.48^{*} \\
(0.32)\end{array}$ & \\
\hline $\begin{array}{r}\text { Last } \\
\text { Election } \\
\text { Religion }\end{array}$ & $\begin{array}{l}-0.03 \\
(0.05)\end{array}$ & $\begin{array}{c}-0.08 \\
(0.07) \\
0.37^{*} \\
(0.23)\end{array}$ & $\begin{array}{c}0.003 \\
(0.05)\end{array}$ \\
\hline$\overline{\sigma^{2}}$ & $\begin{array}{l}2.2^{* *} \\
(0.25)\end{array}$ & $\begin{array}{c}3.3^{* *} \\
(0.42)\end{array}$ & $\begin{array}{c}2.4^{* *} \\
(0.26)\end{array}$ \\
\hline LLR(d.f.) & $56.4(6)^{* *}$ & $48.9(7)^{* *}$ & $58.9(5)^{* *}$ \\
\hline
\end{tabular}

Note: ${ }^{*}$ denotes significant at $\mathrm{p}=0.10,{ }^{* *}$ at $\mathrm{p}=0.05$, one-tailed tests. Standard errors in parentheses 
Table 7: Response Patterns to Seven-Point Scales Perceived Senator's Position By Uncertainty: Form A

\begin{tabular}{|c|c|c|c|c|c|c|}
\hline Position & $\begin{array}{c}\text { Lib / Con } \\
\text { Doubts }\end{array}$ & $\begin{array}{c}\text { Lib / Con } \\
\text { Certain }\end{array}$ & $\begin{array}{l}\text { Abortion } \\
\text { Doubts }\end{array}$ & $\begin{array}{c}\text { Abortion } \\
\text { Certain }\end{array}$ & $\begin{array}{l}\text { Taxes } \\
\text { Doubts }\end{array}$ & $\begin{array}{c}\text { Taxes } \\
\text { Certain }\end{array}$ \\
\hline 1 & 7.1 & 11.2 & 16.2 & 15.3 & 10.9 & 22.2 \\
\hline 2 & 6.4 & 10.2 & 7.1 & 20.3 & 4.6 & 9.3 \\
\hline 3 & 12.8 & 7.1 & 16.2 & 8.5 & 14.4 & 13.0 \\
\hline 4 & 24.4 & 18.4 & 14.1 & 6.8 & 14.9 & 9.3 \\
\hline 5 & 28.2 & 17.4 & 23.2 & 8.5 & 22.4 & 13.0 \\
\hline 6 & 8.3 & 16.3 & 8.1 & 17.0 & 17.2 & 9.3 \\
\hline 7 & 12.8 & 19.4 & 15.2 & 23.7 & 15.5 & 24.1 \\
\hline$x^{2}$ & & $13.1 \ddagger$ & & 17.47 & & $11.7 \dagger$ \\
\hline
\end{tabular}

Note: $\dagger$ indicates a $\chi^{2}$ significant at the $\mathrm{p}=0.10$ level, and $\ddagger$ a $\chi^{2}$ at the $\mathrm{p}=0.05$ level. 
Table 8: Response Patterns to Seven-Point Scales Perceived Senator's Position By Certainty: Form B Lib / Con

\begin{tabular}{r|rcc}
\hline Position & Not & Pretty & Certain \\
\hline 1 & 5.0 & 4.6 & 21.7 \\
2 & 5.0 & 5.5 & 13.0 \\
3 & 13.3 & 16.5 & 6.5 \\
4 & 31.7 & 23.9 & 8.7 \\
5 & 23.3 & 25.7 & 13.0 \\
6 & 13.3 & 12.8 & 6.5 \\
7 & 8.8 & 11.0 & 30.4 \\
\hline$\chi^{2}$ & & & $38.4 \ddagger$ \\
\hline & & &
\end{tabular}

Abortion

\begin{tabular}{r|rcc}
\hline Position & Not & Pretty & Certain \\
\hline 1 & 9.9 & 29.1 & 22.9 \\
2 & 5.6 & 14.6 & 11.4 \\
3 & 21.1 & 7.3 & 2.9 \\
4 & 25.4 & 12.7 & 11.4 \\
5 & 16.9 & 14.6 & 0.0 \\
6 & 5.6 & 10.9 & 8.6 \\
7 & 15.5 & 10.9 & 42.9 \\
\hline$\chi^{2}$ & & & $39.7 \ddagger$ \\
\hline & & &
\end{tabular}

Taxes

\begin{tabular}{r|rcc}
\hline Position & Not & Pretty & Certain \\
\hline 1 & 13.3 & 13.9 & 29.2 \\
2 & 3.1 & 9.7 & 4.2 \\
3 & 24.5 & 11.1 & 12.5 \\
4 & 24.4 & 15.3 & 8.3 \\
5 & 22.5 & 22.2 & 8.3 \\
6 & 5.1 & 15.3 & 8.3 \\
7 & 7.1 & 12.5 & 29.2 \\
\hline$\chi^{2}$ & & & $29.4 \ddagger$ \\
\hline
\end{tabular}

Note: $\ddagger$ indicates a $\chi^{2}$ significant at the $\mathrm{p}=0.05$ level. 
Table 9: Unordered Logit Models of Seven-Point Ideological Scale Responses Likelihood of Placement Relative to Placement at 1 (Form A)

\begin{tabular}{r|cccccc}
\hline Independent & Prob (2) / & Prob (3)/ & Prob (4) / & Prob (5) / & Prob (6) / & Prob (7) \\
Variables & Prob (1) & Prob (1) & Prob (1) & Prob (1) & Prob (1) & Prob (1) \\
\hline Intercept & 2.89 & 1.95 & $3.58^{* *}$ & 2.77 & 2.06 & 0.85 \\
& $(2.68)$ & $(2.1)$ & $(2.0)$ & $(1.98)$ & $(2.13)$ & $(2.13)$ \\
Certainty & -0.45 & $-1.28^{* *}$ & $-1.73^{* *}$ & $-1.15^{* *}$ & $-1.38^{* *}$ & -0.20 \\
& $(0.57)$ & $(0.51)$ & $(0.49)$ & $(0.47)$ & $(0.53)$ & $(0.50)$ \\
Pol. Info. & -0.04 & 0.59 & 0.96 & -.02 & 0.52 & -0.17 \\
& $(0.55)$ & $(0.5)$ & $(0.48)$ & $(0.45)$ & $(0.53)$ & $(0.49)$ \\
Sen. Ideo. & $-0.04^{*}$ & 0.01 & 0.01 & $0.02^{*}$ & $0.03^{*}$ & $0.025^{*}$ \\
& $(0.03)$ & $(0.02)$ & $(0.02)$ & $(0.02)$ & $(0.02)$ & $(0.017)$ \\
Sen. Party & -1.45 & 0.06 & -1.06 & -0.11 & -0.65 & -0.67 \\
& $(1.92)$ & $(1.4)$ & $(1.3)$ & $(1.3)$ & $(1.35)$ & $(1.35)$ \\
\hline \multirow{5}{*}{ Independent } & Likelihood of Placement Relative to Placement at 1 & Form B) & \\
Variables & Prob (2)/ & Prob (3)/ & Prob (4)/ & Prob (5)/ & Prob (6) / & Prob (7) \\
\hline Intercept & 0.51 & 1.78 & -0.15 & $1.95^{* *}$ & -0.53 & -1.08 \\
& $(1.94)$ & $(1.70)$ & $(1.47)$ & $(1.44)$ & $(1.67)$ & $(1.56)$ \\
Certainty & -0.09 & $-1.16^{* *}$ & $-0.67^{*}$ & $-0.85^{*}$ & 0.17 & 0.26 \\
& $(0.63)$ & $(0.62)$ & $(0.52)$ & $(0.52)$ & $(0.59)$ & $(0.56)$ \\
Pol. Info. & -0.09 & 0.39 & 0.28 & -0.07 & 0.38 & $-0.50^{*}$ \\
& $(0.38)$ & $(0.38)$ & $(0.32)$ & $(0.31)$ & $(0.36)$ & $(0.33)$ \\
Sen. Ideo. & -0.02 & -0.01 & $0.02^{* *}$ & 0.009 & 0.01 & $0.03^{* *}$ \\
& $(0.02)$ & $(0.02)$ & $(0.01)$ & $(0.01)$ & $(0.02)$ & $(0.01)$ \\
Sen. Party & 0.12 & -0.30 & 1.11 & -0.06 & -1.19 & 0.59 \\
& $(1.36)$ & $(1.13)$ & $(0.95)$ & $(0.94)$ & $(1.09)$ & $(0.99)$ \\
\hline
\end{tabular}

Note: ${ }^{*}$ indicates statistical significance at the $\mathrm{p}=0.10$ level, and ${ }^{* *}$ at the $p=0.05$ level, both one-tailed tests. Standard errors in parentheses 
Table 10: Placement Models by Uncertainty Survey Form and Uncertainty Response

\begin{tabular}{r|cc|cc}
\hline $\begin{array}{r}\text { Independent } \\
\text { Variables }\end{array}$ & $\begin{array}{c}\text { Form A } \\
\text { Uncertain }\end{array}$ & $\begin{array}{c}\text { Form A } \\
\text { Certain }\end{array}$ & $\begin{array}{c}\text { Form B } \\
\text { Uncertain }\end{array}$ & $\begin{array}{c}\text { Form B } \\
\text { Certain }\end{array}$ \\
\hline Intercept & 4.06 & $3.29^{* *}$ & 4.60 & $3.80^{* *}$ \\
& $(0.61)$ & $(0.76)$ & $(0.96)$ & $(0.65)$ \\
Sen. Ideo. & 0.007 & $0.03^{* *}$ & -0.004 & $0.02^{* *}$ \\
& $(0.007)$ & $(0.008)$ & $(0.01)$ & $(0.007)$ \\
Sen. Party & -0.17 & -0.10 & $-0.89^{*}$ & 0.11 \\
& $(0.47)$ & $(0.57)$ & $(0.64)$ & $(0.49)$ \\
Resp. Ideo. & 0.02 & 0.02 & 0.12 & $-0.10^{*}$ \\
& $(0.07)$ & $(0.09)$ & $(0.12)$ & $(0.07)$ \\
Project. Inter. & 0.001 & $0.004^{*}$ & 0.002 & $0.004^{* *}$ \\
& $(0.001)$ & $(0.001)$ & $(0.002)$ & $(0.001)$ \\
Adj. $R^{2}$ & 0.04 & 0.42 & 0.00 & 0.23 \\
\hline
\end{tabular}

Note: OLS estimates. ${ }^{*}$ indicates statistical significance at the $\mathrm{p}=0.10$ level, ${ }^{* *}$ at the $\mathrm{p}=0.05$ level, both one-tailed tests. Standard errors in parentheses. 


\section{References}

Aldrich, J. H., R. G. Niemi, G. Rabinowitz, and D. W. Rohde. 1982. "The Measurement of Public Opinion About Public Policy: A Report on Some New Issue Question Formats." American Journal of Political Science 26: 391-414.

Alvarez, R. M. 1992. "Issues and Information in Presidential Elections." Ph.D. Dissertation, Duke University, Durham, North Carolina.

Bartels, L. M. 1986. "Issue Voting Under Uncertainty: An Empirical Test." American Journal of Political Science 30: 709-28.

Bartels, L. M. 1988. Presidential Primaries and the Dynamics of Public Choice. Princeton: Princeton University Press.

Brady, H. E. and S. Ansolabehere. 1989. "The Nature of Utility Functions in Mass Publics." American Political Science Review 83: 143-164.

The Bureau of the Census, U.S. Department of Commerce. Statistical Abstract of the United States, 1991, 111th edition. Washington, D.C.

Cook, T. D. and D. T. Campbell. 1979. Quasi-Experimentation. Boston: Houghton Mifflin Company.

Downs, A. 1957. An Economic Theory of Democracy. New York: Harper and Row.

Dubin, J. A. and D. Rivers. 1989. Statistical Software Tools, second version. Pasadena: Dubin-Rivers Research.

Dubin, J. A. and D. Rivers. 1990. "Selection Bias in Linear Regression, Logit, and Probit Models." Sociological Methods and Research, 18: 360-390.

Enelow, J. M. and M. J. Hinich. 1981. "A New Approach to Voter Uncertainty in the Downsian Spatial Model" American Journal of Political Science 25:483-93.

Enelow, J. M. and M. J. Hinich. 1984. The Spatial Theory of Voting: An Introduction. New York: Cambridge University Press.

Franklin, C. H. 1991. "Eschewing Obfuscation? Campaigns and the Perception of U.S. Senate Candidates." American Political Science Review 85: 1192-1214.

Key, V.O. 1966. The Responsible Electorate. Cambridge: Harvard University Press.

Key, V. O., Jr. 1958. Politics, Parties and Pressure Groups, 4th ed. (New York: Crowell).

McKelvey, R. and W. Zavoina. 1975. "A Statistical Model for the Analysis of Ordinal Level Dependent Variables." Journal of Mathematical Sociology 4: 103-20. 
Page, B. I. 1978. Choices and Echoes in Presidential Elections. Chicago: University of Chicago Press.

Palfrey, T. R. and K. T. Poole. 1987. "The Relationship Between Information, Ideology, and Voting Behavior." American Journal of Political Science 512-530.

Shepsle, K. A. 1972. "The Strategy of Ambiguity: Uncertainty and Electoral Competition." American Political Science Review 555-68.

Tobin, J. 1958. "Estimation of Relationships for Limited Dependent Variables." Econometrica, 26: 24-36.

Zaller, J. 1989. "Bringing Converse Back In: Modeling Information Flows in Political Campaigns." In J. A. Stimson, editor, Political Analysis. Ann Arbor: The University of Michigan Press.

Zaller, J. 1991. "Information, Values, and Opinion." American Political Science Review 85: $1213-1237$.

Zaller, J. and S. Feldman. 1992. "A Simple Theory of the Survey Response: Answering Questions Versus Revealing Preferences." American Journal of Political Science 36: $579-616$. 